\title{
Towards New Triple Helix Organisations? A Comparative Study of Competence Centres as Knowledge, Consensus and Innovation Spaces
}

\author{
Martin Meyer ${ }^{1}$, Jari Kuusisto ${ }^{2}$, Kevin Grant ${ }^{3}$, Muthu De Silva ${ }^{4}$, Stephen Flowers ${ }^{5}$, Umair \\ Choksy $^{6}$ \\ ${ }^{1}$ Kent Business School, University of Kent, Canterbury, CT2 7PE (United Kingdom); email:[m.s.meyer@kent.ac.uk \\ ${ }^{2}$ University of Vaasa (Finland), email: rehtori@uva.fi; MIT Sloan School of Management, Cambridge (USA), email: \\ kuusisto@mit.edu \\ ${ }^{3}$ School of Business. University of Dundee, Dundee (United Kingdom), email:k.grant@dundee.ac.uk \\ ${ }^{4}$ Department of Management, Birkbeck, University of London, Malet Street,London WC1E 7HX (United Kingdom); \\ m.desilva@bbk.ac.uk \\ ${ }^{5}$ Kent Business School, University of Kent, Medway, Chatham ME4 4TE (United Kingdom); email: $\underline{\text { S.Flowers- }}$ \\ 418@kent.ac.uk \\ ${ }^{6}$ Kent Business School, University of Kent, Canterbury, CT2 7PE (United Kingdom); email:U.S.Choksy@kent.ac.uk
}

This contribution explores new organisational forms facilitating Triple Helix relations. Analysts have pointed to the blurring of institutional boundaries and the emergence of hybrid organisations at the interface between university, industry, and government. Starting out from the notion that Triple Helix organisations develop and maintain knowledge, consensus and innovation spaces, we explore four cases of competence centres that operate in this context. Comparing them, we identify Finnish SHOK centres as the most radical departure from more traditional forms of university-industry collaboration. These can be characterised as independent legal entities that are involved in integrating a large, possibly cluster-level or technologyfocused network, defining the agenda for specific specialisation areas by engaging in all or most of the Triple Helix spaces. We argue they could be better positioned than existing intermediary organisations to deliver the Triple Helix concept. 


\section{Introduction}

Research over the past two decades suggests that the 'science system' continues to undergo fundamental change (Hessels \& van Lente, 2009). Work on the Triple Helix of universityindustry-government relations (Etzkowitz \& Leydesdorff, 1998; 2000; Etzkowitz et al., 2000) highlights that tri-lateral networks between actors in science, industry and government are growing, and that the boundaries between the three spheres are becoming increasingly blurred. Policy interventions have aimed at finding new ways of producing knowledge that combine both relevance and scientific excellence (Gibbons et al., 1994; Rip, 2004, Hessels \& van Lente, 2009). The rise of 'centres for excellence and relevance', 'collaborative research centres', or 'centres of competence' can be taken as indicators for this new landscape and the beginning of institutionalisation, or rather 'formalisation', of innovation-directed collaborative research (Hellström, 2017; Rip, 2004; Thune \& Gulbrandsen, 2011; Turpin \& Fernández-Esquinas, 2011).

We explore a range of these 'competence centres', some of which are more established while others have emerged more recently. What they share is a mission that refers more or less directly to delivering 'use-inspired basic research', sometimes even explicitly making reference to 'Pasteur's quadrant' and Stokes (1997). We - in pursuit of investigating the characteristics of an ideal type of the Triple Helix Organisation (THO $)^{1}$ - study competence centres from a Triple Helix perspective, particularly how these centres fulfil the mission of producing knowledge 'high' in both industry relevance and scientific excellence.

\section{Dimensions and Functions of Centres in the Triple Helix Context}

This section maps out the functions a Triple Helix-type organisation needs to address in neoinstitutional environments. Etzkowitz's (2008) work allows us to explore the dimensions in 
which organisations, such as competence centres, operate. He distinguishes three types of Triple Helix spaces:

(1) knowledge spaces, which focus on collaboration of different actors to improve local conditions for innovation by concentrating related $R \& D$ activities and other relevant operations;

(2) consensus spaces, that create ideas and strategies in a 'Triple Helix' of multiple reciprocal relationships among institutional sectors (academic, public, private);

(3) innovation spaces, which realise the goals articulated in the previous phase, establishing and/or attracting venture capital.

One could argue a THO serves as a platform, generating the knowledge, consensus, and innovation spaces. Given this task, any 'hybrid organisation' would need to have a coordinating function for the tri-lateral networks which involves strategic planning of research as well as intermediation and mechanisms for the diffusion and commercialisation of innovation. The movement towards Open Innovation (e.g. Chesbrough, 2003) and the involvement of users (e.g. von Hippel, 1988; 2005) as well as the focus on use-inspired research (Stokes, 1997) would suggest a governance structure that is inclusive, giving prominence to users, rather than producers, of technologies. The structure would also need to offer 'rules of engagement' to guide interactions and a set of shared values. Related to this is the question of what is the role of an ideal THO that could define, scope and engage in the areas of use-inspired research. In the following sections we shed light on this query.

\footnotetext{
${ }^{1}$ German sociologist Max Weber introduced the notion of ideal type as a comparative tool in the social sciences. An 'ideal type' is generated by "the one-sided accentuation of one or more points of view" and "by the synthesis of a great many diffuse, discrete, more or less present and occasionally absent concrete individual phenomena, which are arranged according to those onesidedly emphasised viewpoints into a unified analytical construct" (Weber, 1999).
} 


\subsubsection{Knowledge Spaces: Concentration of R\&D Activities and Resources}

Knowledge spaces, often organised as (university-based) centres, bring together several research groups around a shared theme: attracting a greater amount of funding than any single group could, building or acquiring a new facility/infrastructure, and undertaking larger-scale projects (Etzkowitz \& Kemelgor, 1998; Etzkowitz, 2008: 96). Within the Triple Helix context, centres need to be sufficiently broad to generate interest beyond the immediate research, being more widely socially relevant. Topical breadth and relevance will therefore be key descriptors for THOs as well as sufficiently sizeable funding bases to build a variety of activities on.

\subsubsection{Consensus Spaces: Strategic Research Planning and Governance}

Consensus spaces can be considered a neutral ground where actors from different organisational backgrounds and perspectives can come together to "generate and gain acceptability and support for new ideas... knowledge spaces are often transformed from potential to actual sources of economic and social development" (Etzkowitz, 2008: 78). Consensus spaces are the places for strategy formulation and review where actors from different strands of the Triple Helix are brought together. This can be associated with a number of intermediary roles and functions (summarised in Table 1, according to earlier work by Howells (2006). A THO could be expected to carry out such functions.

Table 1 Consensus spaces - intermediation functions

\begin{tabular}{|l|l|}
\hline Type & Function \\
\hline Foresight and diagnostics & $\begin{array}{l}\text { (a) Technology foresight and forecasting } \\
\text { (b) Articulation of needs and requirements }\end{array}$ \\
\hline $\begin{array}{l}\text { Scanning and information } \\
\text { processing }\end{array}$ & $\begin{array}{l}\text { (a) Scanning and technology intelligence - Information scanning and technology } \\
\text { intelligence information gathering and identification of potential collaborative partners; } \\
\text { (b) Scoping and filtering (Selection and clearing function, selection of collaborative } \\
\text { partners) }\end{array}$ \\
\hline $\begin{array}{l}\text { Knowledge processing and } \\
\text { combination/recombination }\end{array}$ & $\begin{array}{l}\text { (a) Combinatorial [Helping to combine knowledge of two or more partners]; } \\
\text { (b) Generation and recombination [As (a) above, but also generating in-house research } \\
\text { and technical knowledge to combine with partner knowledge] }\end{array}$ \\
\hline Gatekeeping and brokering & $\begin{array}{l}\text { (a) Matchmaking and brokering } \\
\text { (b) Contractual advice }\end{array}$ \\
\hline
\end{tabular}

Consensus spaces could deliver the social accountability and reflexivity that Nowotny et al. (2001) and Gibbons et al. (1994) stress as 'grounding' academic research. While consensus 
spaces will involve a multitude of actors, groups of actors may have varying influence. The concern with research and innovation environments is to ensure that activities are userrelevant. $^{2}$ In this business-business context 'users' tend to be user-firms, but they may also be the final benefactors from what industry does. So arguably, a feature of THOs could be the strong influence of user-firms and industry on the boards defining the research agenda. This could be achieved in different ways. While Rip (2011) views the post-modern university as a conglomerate accommodating loosely linked collaborative research centres within the core organisation, Gibbons et al. (2011) make the point that the new 'laboratory spaces', or 'laboratories for the community', that drive research in an application (or 'use') context need not be based in universities at all. This resonates with Etzkowitz's (2008) notion of consensus spaces as neutral ground. ${ }^{3}$

\subsubsection{Innovation Spaces: Innovation and Intermediation Functions}

In Etzkowitz's (2008) framework, innovation spaces are new organisational mechanisms that are concerned with realising the goals identified in strategies developed in the consensus space. The Triple Helix framework conceptualises innovation as a multi-layered process integrating linear, reverse-linear and non-linear processes into a complex adaptive web of relationships and interactions, which is reflected in a broad range of intermediation functions. Table 2 summarises some of these functions based on Howells's (2006) earlier work. ${ }^{4}$ A Triple Helix-based organisation should arguably be able to facilitate a broad range of these functions to its members or partners, whether this occurs in-house or through networks ${ }^{5}$ that may include users.

\footnotetext{
${ }^{2}$ We know from evaluations of established collaborative research centres that academic partners often drive processes (e.g., Reeve \& Anderson, 2009).

${ }^{3}$ Another possibility is to have a 'mixed' model where centres are based at universities but formally independent of them, relying on funding primarily from other sources. Their legal status reflects this situation and is often that of a non-profit limited liability company (Schiller, 2011; Koschatzky \& Stahlecker, 2010).

${ }^{4}$ See also the description of strategic business services by RTOs in Readman et al (2018).

${ }^{5}$ Certain universities have put frameworks in place that address these issues as part of larger networks and systems of collaboration (see Debackere, 2000; Martinelli et al., 2008; Mathieu et al., 2008; van Looy et al., 2003).
} 
Table 2 Innovation spaces - Innovation functions

\begin{tabular}{|l|l|}
\hline Type & Function \\
\hline Testing and validation & $\begin{array}{l}\text { (a) Testing, diagnostics, analysis and inspection } \\
\text { (b) Prototyping and pilot facilities } \\
\text { (c) Scale-up including manufacturing modelling to overcome bottlenecks } \\
\text { (d) Validation, e.g. of analytic methods } \\
\text { (e) Training, Joint training in use of new technologies }\end{array}$ \\
\hline Accreditation & $\begin{array}{l}\text { (a) Specification setter or providing standards advice } \\
\text { (b) Formal standards setting and verification } \\
\text { (c) Voluntary and de facto standards setter }\end{array}$ \\
\hline Validation and regulation & $\begin{array}{l}\text { (a) Regulation } \\
\text { (b) Self-regulation } \\
\text { (c) Informal regulation and arbitration (for example, between consumers and producers) }\end{array}$ \\
\hline Protecting the results & $\begin{array}{l}\text { (a) Intellectual property (IP) rights advice } \\
\text { (b) IP management for clients }\end{array}$ \\
\hline Commercialisation & $\begin{array}{l}\text { (a) Market research and business planning } \\
\text { (b) Sales network and selling } \\
\text { (c) Finding potential capital funding and organising funding or offerings/Early stage capital } \\
\text { (d) Venture capital } \\
\text { (e) Initial Public Offering }\end{array}$ \\
\hline Evaluation of outcomes & $\begin{array}{l}\text { (a) Technology assessment } \\
\text { (b) Technology evaluation }\end{array}$ \\
\hline
\end{tabular}

Source: Adapted from Howells (2006)

In summary, by integrating Triple Helix functions with the roles of innovation intermediaries, we have conceptualised the role of a THO that would enable the production of knowledge with 'high' scientific excellence and user consideration. In the remaining sections we explore with a special focus on competence centres 'how' this 'ideal' type is reflected in the practice of Triple Helix relations and 'why' they are able to act in this particular way.

\section{Methodology and Data}

An interpretive approach was adopted (Schwandt, 1994). The ontological assumption is that reality is constructed within the sphere of innovation systems at the national level and specifically by the personnel at all levels "through their action and interaction" (Orlikowski \& Baroudi, 1991: 14). The epistemological assumption is that "findings are literally created as the investigation proceeds" (Guba \& Lincoln, 1994: 111). We studied THOs in Canada, Finland, Norway, and Sweden. This purposive sample is appropriate, as each country has well documented, discussed and formalised networks at the science/industry interface that provide an infrastructure or service offering in terms of the three Triple Helix spaces presented 
earlier. ${ }^{6}$ We adopted a case studies approach to allow for "an empirical inquiry that investigates a contemporary phenomenon within its real-life context, especially when the boundaries between phenomenon and context are not clearly evident" (Yin, 2003:13), This is important as the selected countries feature 'centres by design' as well as more organically developing agencies enabling the Triple Helix. In some instances, policy stakeholders referred to notions developed in the science and technology policy literature (incl. 'Triple Helix', 'Pasteur's Quadrant', or 'Innovation System') when positioning the centres 7 .

We have first conducted a thematic analysis of existing literature related to THOs, the findings of which were then used to inform 16 elite interviews with stakeholders who have detailed knowledge of the history, political discussions, implementation, operation and evaluation of user-driven research and innovation environments. Elite interviewing allowed us to gain insights from a group of individuals specifically because of who they are, as they have a 'processing power', i.e., they can create and/or nudge a strategic intention a particular way at the policy level. ${ }^{8}$ We initially interviewed 12 policymakers and practitioners, involved in devising, running or evaluating the THOs, interviewing a balanced number in each country. They include representatives of research councils or innovation agencies, industry organisations and competence centre management. We conducted semi-structured interviews

\footnotetext{
${ }^{6}$ Countries with 'corporatist' business and innovation cultures may be more susceptible to government stimulated/ instigated activities leading to the rise of formalised and coordinated efforts to create organisations that set the agenda and run research and innovation activities for entire industrial sectors or clusters. Three of the countries - Sweden, Norway and Finland - are often seen as exemplars of 'corporatist ' societies and business systems, having been labelled 'social democrat', 'meso-corporatist' or 'public institutions-based' (e.g., Whitley, 1992; Lundvall, 1999). Recent work by Etzkowitz (2008) suggests that governments in the Nordic countries still vigorously support collaborative activities of firms in given sectors - if not the creation of clusters.

${ }^{7}$ For instance, all three concepts have featured in material and presentations published by policy stakeholders in Sweden. Indeed, the Swedish Government set up VINNOVA, short for 'Verket för Innovationssystem' or 'Swedish Governmental Agency for Innovation Systems'. VINNOVA has used the Triple Helix as a framework for (regional) innovation policy interventions (e.g., Asheim, 2012) In Norway, Pasteur's Quadrant was used to to position the new CCs in the existing landscape (e.g., Kavlie, 2010). In Finland, innovation policy stakeholders have made frequent use of these frameworks in discussions and commissioned studies and evaluations using them even though policy initiatives may have been less explicit in referring to them.

${ }^{8}$ Early research work on policy making, predominately in the USA related to how Congress developed and implemented new policies, was built around elite interviewing (Dexter, 1970; Fenno, 1978) and Kingdom (1995). In practice, elite interviewing focuses on the top layer of society, whether it is; business, education, sport, science or fashion, however, elite research focuses mainly on political and economic notabilities.
} 
to obtain observations, experiences and attitudes associated with user involvement in hybrid organisational forms. We piloted the use of the interview protocol before conducting the elite interviews, to ensure commonality and standardisation. The interviews were conducted faceto-face or by telephone. Hence, data collection was systematic, ensuring that the collected data are complete for each person on the topics addressed. The interviews focussed on the following themes: the nature and functions of competence centres; organisational structure; governance practices; funding and development process; key activities; evaluation and monitoring. Finally, all the interviewees were encouraged to bring up any comments or additional thoughts they might have. Interview transcriptions were checked by interviewees for factual accuracy. Transcripts were analysed using thematic analysis, reflected against the earlier literature analysis and existing frameworks (Denzin \& Lincoln, 2003). Upon the analysis of these interviews, we conducted four in-depth interviews with managers of one of the centres (i.e. SHOKs) ${ }^{9}$ that -from our analysis - emerged as an ideal THO in order to gain a better understanding of operational aspects and practices adopted. Additionally, subsequent interviews served the purpose of triangulation, improving validity (Downward \& Mearman, 2007).

\section{Findings}

In section 2, we outlined several key features that characterise a THO. Indeed, emerging organisational structures that reflect new institutional arrangements (Leydesdorff \& Meyer, 2010) are evident.

\subsection{How characteristics of THOs are reflected in practice}

In this section we will explore how these ideal-typical characteristics are reflected in practice and whether there are organisations 'out there' that come close to meeting our requirements.

\footnotetext{
${ }^{9}$ Four CEOs of four SHOK Centres - A1: Health and well-being: SalWe Ltd; A2: Built environment innovations: RYM Ltd; A3: Solution Architect for Global Bioeconomy \& Cleantech Opportunities: CLIC Innovation Ltd; A4: Metal products and mechanical engineering: FIMECC Ltd.
} 
Our case studies illustrate the wide range of organisations that operate in the Triple Helix environment:

1. the Swedish VINN Excellence Centres: comprise a group of 20 multi-disciplinary collaborative research centres, typically involving 5-10 members that are located within an active research environment, normally a university, and led by an academic with a mission to deliver research that will yield new knowledge and technology in the form of products, processes and services. The centres are financed by VINNOVA, the country's agency for innovation systems, and industry co-funded. The annual support available for all centres is EUR 20 million. VINNOVA has used the 'Triple Helix' as a framework for innovation policy in the context of the VINN Excellence programme (e.g., Asheim, 2012).

2. the Norwegian Centres for Research-based Innovation (CRI): comprises 14 centres. Collectively they receive EUR 17.5 million of public funding annually. These CRIs focus on facilitating 'active alliances' and developing 'industrially-oriented research groups', and encouraging enterprises to innovate by placing stronger emphasis on long-term research. The centres also incorporate a training and technology transfer function. The CRI centres seek to strike a balance between industry and academic interests, and official presentations locate them in 'Pasteur's quadrant' (e.g. Kavlie, 2010).

3. the Canadian Business-led Networks of Centres of Excellence (BL-NCE): comprise 4 large-scale, collaborative networks, led by private sector consortia, with a mission to generate new technologies and products that produce 'knowledge economy' jobs. BLNCEs have a broad outlook, with a comparatively large funding base at EUR 1.7-2.5 million per year. The Canadian BL-NCE concept represents a further, 'downstream' development of the generally successful, more research oriented and academic led Networks of Centres of Excellence (NCE) programme. 
4. the Finnish Strategic Centres for Science, Technology and Innovation (SHOK):

comprises 6 very large centres, organised as non-profit, limited liability companies, with often more than 30 shareholders and 100 programme and project partners associated. The SHOKs cover entire clusters and industrial sectors. Launched in 2009/10 with a mission to enable 'industrial renewal' and generating 'breakthrough innovations', SHOKs are a collaborative venture between the Ministry of Employment and Economy (MEE), the Finnish Funding Agency for Technology and Innovation (Tekes), the Academy of Finland and the Confederation of Finnish Industries (EK). Further key players are the industrial user representatives who take the lead in defining the strategic research agenda for each SHOK. The centres receive EUR 50 million funding per year and can develop and run cluster and industry-level research, development and innovation programmes.

Appendix One offers brief overviews of all the centres. All of them have very specific characteristics and differ considerably in how they operationalise their strategic intent. This is in keeping with their ideological focus. Following the structure developed in section 2, we summarise our findings with respect to the role of each centre in Table 3.

In terms of knowledge spaces, the focus of the centres varies from setting the research agenda for an entire cluster or industry to performing rather specific research activities. This is also reflected in the budget scale, which varies considerably from under EUR 1 million to EUR 50 million and more. In one instance, a centre has received delegated responsibility to develop and administer programmes. In terms of consensus spaces, the centres differ considerably in their organisational set-up (from being university-hosted to being incorporated as a limited liability company), the role and involvement of industry users as well as the extent to which they cover intermediary functions. Functions with respect to innovation spaces are also addressed to varying extent. 
Table 3. Competence Centres, their research governance and intermediary innovation functions

\begin{tabular}{|c|c|c|c|c|}
\hline Centre: & $\begin{array}{c}\text { VINN } \\
\text { Excellence } \\
\text { Centres }\end{array}$ & $\begin{array}{l}\text { CRI Centres for } \\
\text { Research } \\
\text { based } \\
\text { Innovation }\end{array}$ & $\begin{array}{c}\text { BL-NCE } \\
\text { Business led } \\
\text { Networks of } \\
\text { Centers of } \\
\text { Excellence }\end{array}$ & \begin{tabular}{|c|} 
SHOK \\
Strategic \\
Centres for \\
Science \\
Technology and \\
Innovation
\end{tabular} \\
\hline Country: & Sweden & Norway & Canada & Finland \\
\hline \multicolumn{5}{|l|}{ 'Knowledge spaces' } \\
\hline 1. Research agenda for sector or cluster & & & & $\checkmark$ \\
\hline $\begin{array}{l}\text { 2. Delegated authority to allocate substantial amounts of } \\
\text { research funding }\end{array}$ & & & & $\checkmark$ \\
\hline 3. $\quad$ Annual budget scale & + & ++ & ++ & +++ \\
\hline 4. Scope of topics & Thematic & Thematic & Cluster & Cluster \\
\hline \multicolumn{5}{|l|}{ ‘Consensus spaces' } \\
\hline 1. Organisational form & Hosted & Hosted & Independent & Independent \\
\hline 2. Industry role & + & ++ & +++ & +++ \\
\hline 3. $\quad$ Foresight and diagnostics & & & $\checkmark$ & $\checkmark$ \\
\hline 4. $\quad$ Scanning and information processing & & & $\checkmark$ & $\checkmark$ \\
\hline $\begin{array}{l}\text { 5. Knowledge processing and combination/ } \\
\text { recombination }\end{array}$ & $\checkmark$ & $\checkmark$ & $\checkmark$ & $\checkmark$ \\
\hline 6. $\quad$ Gatekeeping and brokering & & & $\checkmark$ & $\checkmark$ \\
\hline \multicolumn{5}{|l|}{ ‘Innovation spaces’ } \\
\hline 1. Testing and validation & $\checkmark$ & $\checkmark$ & & \\
\hline 2. $\quad$ Accreditation & & & & \\
\hline 3. Validation and regulation & & & $\checkmark$ & $\checkmark$ \\
\hline $\begin{array}{ll}\text { 4. } & \text { Protecting the results } \\
\end{array}$ & ** & $\checkmark$ & $\checkmark$ & $\checkmark$ \\
\hline 5. $\quad$ Commercialisation & ** & $v^{*}$ & $\checkmark^{*}$ & $\checkmark^{*}$ \\
\hline 6. Evaluation of outcomes & $\checkmark$ & $\checkmark$ & $\checkmark$ & $\checkmark$ \\
\hline \multicolumn{5}{|l|}{ Code Chart: $\quad \checkmark$ (indic } \\
\hline $\begin{array}{l}\text { * By participating companies as gover } \\
{ }^{* *} \text { Encouraged by funding organisation }\end{array}$ & $d$ by the centre / & network agreement. & & \\
\hline
\end{tabular}

\subsection{How the competence centres succeed as a THO}

Our findings on the success of these centres and the enablers of success suggest that all four cases have aspects and features that can be associated with the THO. It is evident that the emergence of such organisations can be an incremental, developmental process a more radical departure from university and research centre-hosted units. The Swedish, Norwegian and Canadian cases offer a perspective on a more incremental approach, with the Swedish centres more closely associated with the university as a host organisation than the Norwegian centres, and the Canadian networks having taken the next step of becoming an independent structure. 
The Canadian example is strong at building networks and implementing an industry-led agenda while the other two Norwegian and Swedish cases may be taken as illustrations of collaborative research centres that can evolve into hybrid organisations as part of the fabric of the post-modern university that Rip (2011) outlined.

The Finnish SHOK centres can be seen as a more radical departure from university and research centre-hosted units, characterised by integrating Triple Helix actors and networks at a larger scale, making a strong and sustained effort to involve the industry 'user' side, and occupying roles across all three Triple Helix spaces.

Below, by focusing on each organisation, we discuss how the competence centres deliver the Triple Helix roles drawing on our elite interviewees' assessments and evaluation reports. We distinguish between centres that have developed incrementally and an organisation that from its inception has included a wide range of features of an 'ideal-type' THO.

\subsubsection{Becoming a THO incrementally}

Our evidence suggests that the Swedish VINN Excellence Centres have proven to be successful academic-led research environments achieving a high degree of industry impact (for validity see the recent evaluation by Reeve \& Anderson, 2009). It was evident that despite the relatively small size, they have reached critical mass in specific, well-defined areas. Many of them have built on solid university-industry networks of competence centres that were established in the 1990's (Arnold et al., 2004; Knee \& Meyer, 2007). An interim evaluation of the VINN Excellence Centres (Reese \& Anderson, 2009) was favourable, highlighting successes in 'creating effective partnerships between universities and industry' (p. 10). The follow-up study (Stern et al, 2013) explored specifically the long-term industrial 
impact of Swedish Competence Centres and identified a wide range of direct and indirect impacts as well as spill-over effects.

The Triple Helix framework has been used in the Swedish research policy discourse; a Swedish-language report on the Triple Helix (Etzkowitz, 2005) had considerable influence. The Swedish VINN Excellence programme has explicitly embraced the concept of 'Triple Helix' (Asheim, 2012) and a complementary programme, 'Vinnväxt' to promote sustainable regional growth, also incorporates the notion (Ranga \& Etzkowitz, 2013). Communicating the meaning of the 'Triple Helix' has been subject of a separate set of interventions which referred to the knowledge, consensus and innovation spaces in Etzkowitz' (2005) framework (Gennerud et al., 2009).

The interim evaluation of the VINN Excellence Centres (Reese \& Anderson, 2009) that detailed 22 recommendations across 9 areas further validated our findings from our interviews. The recommendations were rather specific and technical in nature but suggested that certain centres should embrace the opportunity to improve their governance and management structures and processes. With respect to Triple Helix innovation spaces, the evaluators asked policy stakeholders to 'provide significant input to the process of resolving centre IPR [Intellectual Property Rights] issues' (recommendation 18), which would give centres and their stakeholders more confidence to engage in activities related to knowledge and innovation spaces. Policy stakeholders were also encouraged to create and implement ways of sharing best practice and to find mechanisms to include SMEs among their industry partners (recommendation. 19), as well as to develop further entrepreneurial skill sets (recommendation. 20), which - as per our evidence - would indeed enhance centres' performance in all the three types of spaces, particularly supporting to deliver user-driven industry/cluster impacts. 
Our interviews suggest that the larger Norwegian CRIs have a remit that focuses explicitly on industrial, or firm-based, users. In addition to our interviews we have also considered the midway evaluation report (RCN, 2010). In our interviews, CRIs were seen very much as an overall success. Their industry impact was highlighted in particular. This outcome of the initial stage has led to the extension of funding for all centres (Kavlie, personal communication, 2011). The latent tension between some host institutions and the centre as a unit was viewed a key area for improvement that came up in interviews and was also subsequently confirmed in the evaluation. The host institutions are still keen to embrace the centre as their own activity rather than viewing it as the 'neutral consensus space' that Etzkowitz (2008) posits. On several occasions, the CRI centres were identified by the elite experts as 'projects' at their host institutions rather than as the 'independently operating units' in the eyes of the evaluators. At the individual centre level, stakeholders tended to omit the centre as their affiliation due to 'host institution demands' (RCN, 2010). Our interviewees and the evaluation reports recommended the need to establish clearly defined procedures and management groups to ensure the participation of both scientists and user partners in monitoring and planning of projects and project portfolios. This may point to the constant challenge of harmonising the interests and needs of user-driven basic research and those of mainstream higher education. One of the report's 6 recommendations highlighted the need for centres to adopt a differing governance system, which would enable centres to select their Board chairperson from amongst the user partners (RCN, 2010), which would improve centre's ability to deliver user-driven industry/cluster impacts.

As per our analysis of elite interviews and evaluation reports, it was evident that the Canadian Business-Led NCEs were designed to have even more industry ('user') involvement than the Norwegian CRIs insofar as the BL-NCE is private sector led, with a manager typically not coming from academe, the consortia representing predominantly the private sector, and the research agenda of the BL-NCEs being shaped and underwritten financially to very large 
extent by the private sector (see also Grant et al., 2014). The BL-NCEs have built upon and extended a successful programme of collaborative research centres, namely the Networks of Centres of Excellence (NCE) programme launched in 1989, involving some 1,800 organisations in 24 centres (Knee \& Meyer, 2007). This organisational form has addressed various stages of the innovation life cycle, most recently commercialisation of activities and accommodating the national level policy requirements to engage in and with SMEs concerning knowledge transfer and innovation activities (Government of Canada, 2009; 2011).

Our interviews suggest that the comparison between the Canadian case and the other two centres discussed previously offers the opportunity to explore how the 'competence centre' concept has evolved over time, and to identify what distinguishes user-firm or industry-driven organisations from more research focused organisations. Unlike academic-led NCEs, BLNCEs are defined as not-for-profit consortia representing the private sector, with a director as network leader and connector rather than a university professor or clinician as a principal investigator. The research agenda is solely private sector-driven and orientated rather than 'university strategically determined' (for validity, please see Zulkifli, 2009). This is reinforced by private-sector participants committing to cover at least $50 \%$ of direct research and $25 \%$ of administrative costs. An interesting distinction of the BL-NCEs from the initial programme (and most of the other initiatives discussed in this paper) is that their funding is not renewable (ibid.). Another interesting aspect is how and where the work is located in a hybrid organisation, perhaps highlighting the nature of this effort being more a project than an organisation with a 'sense of place'. ${ }^{10}$ The latest evaluation of BL-NCE (Performance

\footnotetext{
${ }^{10}$ While the BL-NCE's have a clear focus and an industry-driven mission and research agenda, their nature as hybrid organization also raises questions about a 'sense of place'. As one respondent put it (Interview participant $\mathrm{C} 1$ : professor of engineering), "[h]aving worked on a national project of strategic importance on renewable energy, I am still confused as to who owns the idea. Is it me? My university? The Canadian government? All I know is the work is good; working with similar interested and like-minded colleagues is fantastic [...]". Perhaps
} 
Management Network, 2012) has found the programme is showing early success pointing to "project portfolios that address the needs of network members" (p. v), characterising them as efficiently managed (p. vi). It is also reported that the networks exceed their matching funds requirement and a substantial number of highly qualified personnel have participated in the networks' training programmes. The intellectual property arrangements are seen to "facilitate the development of multisectoral, multidisciplinary R\&D teams or projects” (ibid.). It has also been highlighted the need to establish "a better linkage between the network and program level outcomes", which would facilitate the delivery of cluster level impacts.

\subsubsection{An 'ideal type' of THO from inception}

Unlike Swedish VINN Excellence Centres, the Finnish SHOKs have not explicitly embedded the notion and philosophy of 'Triple Helix' in their functioning and practices. Nevertheless, our findings suggest that the Finnish SHOK centres resemble the closest organisational form of an 'ideal type' of THO discussed earlier. SHOKs were launched in 2009, later than the other Northern European centres. Their conceptualisation was influenced by discussions about the Joint Technology Initiatives that were planned under the EU FP7 programme. As was identified in the elite expert interviews, SHOKs can be viewed as a new type of public-private partnerships actively involved in all three Triple Helix spaces, delivering research and its use. Both Tekes, as government funding body, and private companies have played an important role in the formation and funding of the SHOK initiative (Lähteenmäki-Smith et al., 2013).

Unlike the other centres we surveyed, they are organisations in their own right, alongside universities, industry and government. The status of the SHOK centres as limited liability companies has some clear benefits and limitations. As confirmed by our elite expert interviews, the governing structure, responsibilities and principles are clear and enforceable

this is a characteristic of an organizational entity with a fixed 4-year life time - more a project than a location or place one can associate with. 
by company and commercial law statute. ${ }^{11}$ However, due to this legal form, contractual issues have reportedly emerged, for example, about intellectual property (IP) rights.

According to our interviewees, this one area has 'plagued' the incorporation and start-up phase of the centres (see also Gustafsson \& Järvenpää, 2018).

Nevertheless, our interviews with managers suggested that the benefits of its legal form outweigh challenges, particularly in the light of the measures taken to minimise IP issues. One of such mechanisms that has also ensured the delivery of cluster wise impacts was the collaborative designing of centres' strategic direction and research agenda by their partners comprising large and small businesses, research organisations and policy makers:

"The shareholders, who are companies, universities and government, are creating FIMECC's research strategy. The shareholders decide what kind of programmes we have in Finland and what kind of programmes not" (A4)

They have set up a complex structure including a board of directors, a company steering group, an R\&D council, as well as strategic steering groups to develop and agree on a strategic research agenda. Many of these boards and groups have rotating memberships to ensure broader engagement.

It was evident that this approach has created a platform for exchange, even a cluster-level consensus space in the Triple Helix sense. Their size and strong funding base reflect their remit of industrial renewal at cluster level. This includes the allocation of substantial amounts of programme rather than project funds. To illustrate, a single SHOK has launched 6 programmes that amount to EUR 185 million over a 5-year period (Kuusisto \& Meyer, 2010).

\footnotetext{
${ }^{11}$ For instance, as one interviewee puts it, "[t] he fact that SHOKs are organised as limited companies facilitates business executives' commitment to and involvement in their activities. For instance, when they come to SHOK board meetings, they know instantly what the key tasks of the board are. They are used to this type of work and process in their business context, so the process outline and the type of topics to be addressed are very clear for them right from the start. We can then fully and effectively focus on the important substance issues. At the same time, if we speak of a university-led organisation that has its own ways and operational practices, the situation is quite different. Business managers are often less motivated and committed, as they do not have a clear idea of the objectives and how the process works. So, in this way, SHOKs as a limited companies offering an ideal framework and process for business leaders to commit to the work. It rather brings these two worlds together" (Interview participant 5: senior manager).
} 
The scale of the centres, combined with the heterogeneity of their partners, justifies the need to have an elaborated governance and management structures than in most of the other centres we studied. Bringing a large network of small players for the collaboration was a striking contrast between SHOKs and other centres, which in managers' and elite interviewers' opinion has enabled them to translate small players' radical thinking and innovation into cluster wide impacts:

"We have 34 shareholders but we have connections to 160 companies which operate in our programmes and out of these 160, half are SMEs and we have been quite successful in linking SMEs with other players.....Two weeks ago I took one of the Finnish SMEs to Germany and it's rather classical that RTOs are likely to work with universities, large companies and other RTOs, but we tend also to work with other SMEs." (A 4)

SHOKs' consensus space support small players to effectively interact with other actors of an industry cluster by overcoming communication and resource difficulties that often inhibits potential collaboration:

"The first once is that since we, FIMECC, are owned by big companies and universities and research institutions, they are our shareholders, they all know that a lot of new innovation, a lot of radical thinking, comes from smaller companies which are not established, which don't have rigid businesses and the bigger companies and big universities, they want to cooperate with SMEs, so this is a very innovation-oriented reason. All the shareholders, they know that it is not easy to communicate with SMEs, they many times do not have too much resources, or people who are interested in research or who are research-trained who can talk with the university researchers, but these are practical problems. In principle, many people think that there is a lot of innovation potential in SMEs" (A4)

Since the launch of the SHOK centres, a number of assessments and evaluations programme have examined their work. An early, survey-based assessment of four of the six centres by the Finnish Federation of Industries (Annala \& Ylä-Jääski, 2011) confirms what emerged from our elite expert interviews: that SHOK programmes are 'successfully industry-driven' and 'genuine collaboration' occurs. According to the report, the centres have provided a 'brand new type of information exchange', resulting in additionalities, such as the formation of consortia and collaborations with new partners. The report states that this "would have hardly 
been possible without the SHOK concept" and that "SHOKs have provided the necessary framework” (Annala \& Ylä-Jääski, 2011: 4).

The interviews with managers illustrated that the adoption of unique interaction practices has enabled SHOKs to establish genuine and industry driven collaborations. They believe that, institutional level collaboration is driven by 'people' who are actively engaged in project/interaction activities. Hence, they support interactions between 'people' from different institutions, through face-to-face meetings, workshops, and seminars, spending time with them to understand their objectives, goals, and needs, reaching a shared understanding with partners, designing strategies and road maps for partners as to how to interact with 'people' from different institutions, helping to develop trust, and providing a trusted platform for collaboration:

"I believe face-to-face meetings is most important. You cannot build cooperation by building reports so what we do is organising meetings, workshops, seminars; places where they can meet and shape their views. That is what I believe is the most beneficial way of leading cooperation." (A1)

"I think there is not an easy way. You just must spend time with the partners, with the person behind some organisational structure. I don't believe that organisations do things, I believe that people do things. It means spending time with people and through that we can achieve our objectives [...] It's how you interact with people from heterogeneous backgrounds, how you appreciate the partners and how you do new things with new partners and it takes unfortunately time but I don't see any other mechanism to carry out this with people." (A4)

However, a more recent, influential evaluation has taken a decidedly more sceptical view (Lähteenmäki-Smith et al., 2013). While the evaluation reports a comparatively positive view of companies and their representatives towards SHOKs and characterises them as 'industrydriven', it also observes that SHOKs have "struggled to convince the academic community of the value of participation of the concept as a whole" (p. 13). The evaluators criticise that the centres' agendas tended to be based "more on compromise than on a shared commitment to achieving excellence" (ibid.). Another important observation from a Triple Helix perspective concerns stakeholder involvement. Here, the report suggests that "public sector decision- 
makers and consumer groups ... should be better integrated into many of the SHOK's

activities" (p. 16). Our interviews with centre managers revealed that they have taken several measures to address this criticism and the centres are now more inclined to achieving goal congruence between members coming from different spheres, which drives shared commitment to achieving excellence:

"The shareholders, who are companies, universities and government, are creating FIMECC's research strategy. The shareholders decide what kind of programmes we have in Finland and what kind of programmes not. We take such criticisms seriously and try to develop programmes that would help everybody to generate value. Throughout the programme from inception until completion we evaluate the objectives and needs of partners and take necessary actions to incorporate their needs to reach a win-win situation" (A4)

Nevertheless, the managers have acknowledged that reaching shared understanding and goals between a wide array of actors with diverse needs is not always easy. Collaboration is difficult when partners have unmanageable levels of diverse interests, goals and motivations. In managers' experience, one way of overcoming this is through shaping the interests of actors within an innovation ecosystem in pursuit to increase the chances of reaching a shared understanding and mutuality between the participating actors which is important for successful collaboration. They, in collaboration with their existing members, shape the ecosystem, by way of influencing EU policy direction, EU work programmes, and participating in European Technology Platforms and structures associated with Public Private Partnerships:

"Finland has been active in some Public-private partnerships and I participated in 'healthy diet for a healthy life' for a couple of years when they built their activities and did their joint actions. This PPI also do their research agendas and we participating in that work because we wanted to have those things that were important for Finland also involved in European agenda." (A 1)

"I'm personally a member of the EFRA partnership board for the Factories for the Future Research organisation ...this is the method, how we discuss in general PPP initiatives and technology areas." (A4)

Also, unlike the other centres that we have studied that tend to have a more focused innovation engagements, SHOKs are reported to support innovation across Technology 
Readiness Levels (TRL), ranging from TRL1 to 7 and aiming to expand up to $9 .{ }^{12}$ This wider

engagement enables them to incorporate the goals of a broad range of members, who are

generally at different stages of the innovation process. It was also evident that the centres -

instead of technology push approach - attempt to engage in user-led co-creation, which

involves close interactions between a wide arrays of actors of an ecosystem or a service

network - by taking user perspective -throughout the innovation process from concept to

market (McColl-Kennedy et al. 2012). These innovation approaches facilitate their role as

THOs, considering the variety of activities and diversity of partners:

\begin{abstract}
"But of course as a limited company, FIMECC tries to be a manager, a coordinator, some kind of network administrator. So our role is somehow divided in to two; what we do as a mindset as an open innovation-boosting company and what we practice as a management side to boost this innovation. We would like to call ourselves a cocreation organisation, because we try to lever the life of customers, future consumers, the future needs of the world and try to develop things and services and innovations for the future needs for the future world, not only to develop technology as such and then push it to the market." (A4)
\end{abstract}

The managers have also revealed that the move towards cross-industry collaboration, set with the remit to increase opportunities for greater value creation, allows them to fulfil the needs of a wide array of partners minimising the compromising of their goals. Cross-disciplinary engagement in turn signifies all three spaces of SHOKs:

\begin{abstract}
"There are some groups within for example one industry area where there has been strong cooperation for a long time but I think the most important part of our work is building cross-industry cooperation between the companies who are not typically working with each other, for example technology and service companies. I believe they bring benefit from both of them, but in many cases they are working separately and what we are trying to do is like linking them. Also the cooperation between industry and academia is very important; build trust and build understanding and talk to each other and work together for solutions to problems. The most challenging things are cross-industry and also multi-discipline research because those parties have not used to work with each other and we are helping them to do that." (A1)
\end{abstract}

\footnotetext{
${ }^{12}$ TRL 1- Concept proposed with scientific validation; TRL 2- Application and validity of concept validated or demonstrated: TRL 3 - Experimental proof of concept completed: TRL 4 - Production validated in lab environment: TRL 5 - Basic capability demonstrated: TRL 6 - Process optimised for production rate on production equipment: TRL 7 - Capability and rate confirmed: TRL 8 - Full production process qualified for full range of parts: TRL 9- Full production process qualified for full range of parts and full metrics achieved

${ }^{12}$ TRL 1- Concept proposed with scientific validation; TRL 2- Application and validity of concept validated or demonstrated: TRL 3 - Experimental proof of concept completed: TRL 4 - Production validated in lab environment: TRL 5 - Basic capability demonstrated: TRL 6 - Process optimised for production rate on production equipment: TRL 7 - Capability and rate confirmed: TRL 8 - Full production process qualified for full range of parts: TRL 9- Full production process qualified for full range of parts and full metrics achieved (Mankins 1995)
} 
"People are resistant to breaking barriers of working with other research areas.

Hence, there is a need for coordination, which we fulfil' (A2)

As discussed, of all the centres that we have studied SHOKs seem to be closest to an 'ideal' type of THO, successfully engaging in all three spaces to deliver cluster wide impacts. Their success could be attributed to the formation as an independent entity, having a governance structure that allows partners to decide the strategic direction, actively engaging in bridging a large network of divers cluster actors, supporting close interactions between 'people' within institutions, having a more long-term and broader focus involving in programmes rather than projects, engaging in diverse range of innovation from concept to market with more user-led co-creation approach with cross-disciplinary focus and influencing the ecosystem.

\section{Discussion and Conclusions}

\subsection{Competence Centres and their approach towards the Triple Helix}

In this paper we have explored the extent to which competence centres in four countries resemble organisational forms or configurations that merit description as a THO. Historically, 'hybrid organisations' have been anchored in one of the Triple Helix spheres and addressed some of the functions that can be associated with the Triple Helix spaces. There have so far been very few centres that transcend knowledge, consensus and innovation spaces. While the Norwegian and Swedish centres can be viewed as 'extensions' of the 'post-modern university' (Rip, 2011), the Canadian model seems to be on its way to becoming a distinct THO. The recent evaluation certainly points to early successes. The Finnish SHOK centres appear to be a research and innovation environment that comes closest to the 'ideal type' that we outlined earlier on the basis of research by Etzkowitz and colleagues.

The defining characteristic of the SHOK centres is that they attempt to integrate all Triple Helix spaces and related functions into a formalised structure that covers an entire cluster or 
industry. In that sense, the SHOKs can be considered a structural innovation (Howells and Edler, 2011). They represent both a new organisational form and a new configurative arrangement. A distinguishing feature of SHOKs is their (delegated) authority to develop and approve large-scale technology programmes. Generous funding arrangements mean that the strategic research agendas, which are defined by all relevant stakeholders for an entire cluster or industry, could actually be implemented. This way consensus spaces can potentially be transformed from 'talking shops' to potentially powerful 'decision spaces' that actually influence the way in which a cluster or industry develops. With strong industry-driven efforts, however, the new organisations must be wary of the push from some commercial partners for 'immediacy of solutions' rather than fulfilling their own vision and striving towards bridging the gap between theory and practice and the development of new types of knowledge (Van de Ven \& Johnson, 2006). The centres define a strategic research agenda that strikes a balance between basic and applied research by supporting partner engagement in innovation across a wide range of TRL levels, including cross-industry programmes. The practices successfully adopted by SHOKs in response to the evaluation that has been critical about the relative dominance of established industry players in driving research agendas, highlight how an organisation could move from Edison's to Pasteur's quadrant, securing both business and academic buy-in and an opportunity to deliver both user-driven and breakthrough innovation.

Governments will need to ensure that specific checks and balances are put into place to ensure these hybrids are ambidextrous in responding effectively to the needs of both stake- and shareholders. They will also need to ensure accessibility of these new dynamic organisations by those who are currently not geared up or feel able to take advantage of what they offer. 


\subsection{Towards an 'ideal typical' THO}

This section aims to describe what shape an 'ideal typical' THO takes. The key challenge in creating viable and effective tri-lateral networks is the need to attract representatives from all the strands of the Triple Helix who have the credibility and decision-making power to instigate and expedite action (Etzkowitz, 2008). Organisations combining a range of services are likely to be of greater benefit to members than a plethora of organisations that take on separate tasks (e.g., Göktepe, 2008; Meyer et al., 2007). The more functions an organisation combines across the three Helix spaces, the more attractive it would be to its members. Arguably, an ideal type organisation would then encompass all the functions that were outlined.

The discussion of consensus spaces in the previous section has illustrated the need for creating a neutral ground for exchange between the various parties to take place. This requirement is best met by an independent organisation, a legal entity in its own right that can balance out the interests of all stakeholders. Such an organisation can be envisaged to exist in a different organisational context than the partners in academe, industry and government, allowing it to act as a truly linking structure located at the centre of tri-lateral networks. Managing a better linkage between cluster wide partners, who collaboratively set the agenda of the neutral space, ensures the delivery of cluster wide impacts minimising common compromising associated with collaboration with diverse partners.

The discussion surrounding knowledge spaces has highlighted how important reaching critical mass is, and that interest in a network is related to the power it has to shape and influence developments. Organisations and networks with powers to attract or grant substantial funding will exert a pull on other actors - which is arguably very much in line with the Matthew effect (van Looy et al, 2003). In some countries, learned societies or research institutes have taken on 'sovereign' functions and roles in administering government R\&D programmes, 
supporting applicants in preparing their proposals and informing the decision-making process of the respective ministry or agency (e.g. the so-called 'Projektträger' in Germany; see e.g., Edler \& Kuhlmann, 2008). In others, ministries delegate responsibilities, including resource allocation, to agencies (e.g. Braun, 2008; Pelkonen et al., 2008). It may be possible to take this process of delegation a stage further. A hybrid organisation could take on this role and introduce a user perspective. ${ }^{13}$ If such an organisation is conceptualised as an independent entity, conflict of interest issues (which exist at times in current collaborative research centres) can also be minimised.

All in all, we can highlight what makes it possible to become an ideal type THO:

- set up with a high level of autonomy, e.g., as a legal and independent entity,

- integrate a large, possibly cluster-level or technology-focused network,

- adopt interaction practices to support collaboration between heterogeneous actors,

- act as a neutral place, the strategic direction of which is collaboratively set by partners representing diverse cluster actors,

- engage in consensus building by defining a research and innovation agenda for its area,

- involve in influencing the ecosystem in pursuit of developing an environment conducive for cluster performance,

- drive change and collaboration by defining and implementing large-scale research programmes,

- act as a hub for intermediary and innovation activities, covering most if not all of them.

\footnotetext{
${ }^{13}$ A model for this emergent public-private partnership may be the European Commission's Joint Technology Initiatives, which are a major new element of the EU's 7th Research Framework Programme. They provide a way of creating new partnerships between publicly- and privately-funded organisations involved in research, focusing on areas where research and technological development can contribute to European competitiveness and quality of life. The Commission expects this new model of public-private partnership to stimulate additional European research investment, build critical mass by uniting currently fragmented efforts, and ensure effective and efficient programme management.http://europa.eu/rapid/pressReleasesAction.do?reference=MEMO/07/191
} 
It goes without saying that what we present as an idea-typical THO needs to stand the test of time. It is very much a new and different form of facilitating institutionally, or rather organisationally, interaction across the three different spheres.

\section{Acknowledgements}

Earlier versions of this paper were presented at a thematic workshop at the $9^{\text {th }}$ Triple Helix

Conference, Stanford, July 2011, and subsequent seminars at the Universities of London,

Vaasa, and Warsaw. We would like to the thank seminar and workshop participants for their

feedback. In particular, we are grateful to Koenraad Debackere, Dirk Libaers, and Stuart

Macdonald for their valuable comments on earlier drafts of this paper. We also would like to

thank the two anonymous reviewers for their helpful suggestions. Three of the authors

gratefully acknowledge financial support from from TEKES and the Finland Distinguished

Professor (FiDiPro) programme.

\section{References}

Annala, K. and Ylä-Jääski, J. (2011) Strategy, Excellence, Centres? The Strategic Centres for Science, Technology and Innovation (SHOKs) CLEEN, FIMECC, Forestcluster and TIVIT from the Company Perspective. The Federation of Finnish Technology Industries. Helsinki, Finland.

Arnold, E., Clark, J., Bussillet, S. (2004) Impacts of the Swedish Competence Centres Programme 1995-2003. Summary Report. Vinnova Report \#VA 2004:05. Stockholm: Vinnova.

Arnold, E., Clark, J., Javorka, Z., 2010. Impacts of European RTOs: A Study of Social and Economic Impacts of Research and Technology Organisations. Report to European Association of Research and Technology Organisations (EARTO), Technopolis Ltd, Brighton.

Asheim, B. (2012) Universities and Triple Helix collaboration - the Swedish case in a comparative Scandinavian perspective. Presentation at OECD Roundtable on Higher Education in Regional and City Development: Universities for skills, entrepreneurship, innovation and growth. Paris: OECD, 20 September 2012.

Braun, D. (2008) Lessons on the political coordination of knowledge and innovation policies. Science and Public Policy, 35(4), 289-298, DOI: 10.3152/030234208X310347

Chesbrough, H. (2003) Open Innovation: The New Imperative for Creating and Profiting from Technology. Boston, MA. USA: Harvard Business School Press.

Debackere, K. (2000) Managing academic R\&D as a business at K.U. Leuven: context, structure and process. R\&D Management, 30 (4), 323-328.

Denzin, N.K., and Lincoln, Y.S., (eds.) (2003), Handbook of Qualitative Research. Third edition. Thousand Oaks, CA: Sage.

Dexter, L. A. (1970) Elite and Specialized Interviewing. Evanston: Northwestern University Press.

Edler, J. and Kuhlmann, S. (2008) Coordination within fragmentation: governance in knowledge policy in the German federal system. Science and Public Policy, 35(4), 265-276; DOI: 10.3152/030234208X310329.

Etzkowitz, H. (2005) Trippelhelix - den nya innovationsmodellen. Högskola, näringsliv och myndigheter i samverkan. Stockholm: SNS förlag.

Etzkowitz, H. (2008) The Triple Helix: University-industry-government. Innovation in Action. London: Routledge. Etzkowitz, H. and Kemelgor, C. (1998) The role of centres in the collectivisation of academic science. Minerva, 36 (3), 231-268. 
Etzkowitz, H. and Leydesdorff, L. (1998) The Triple Helix as a Model for Innovation Studies. Science \& Public Policy 25 (3), 195-203.

Etzkowitz, H. and Leydesdorff, L. (2000) The dynamics of innovation: from National Systems and "Mode 2" to a Triple Helix of university-industry-government relations. Research Policy 29 (2), 109-123.

Etzkowitz, H., Webster, A., Gebhardt, C. and Cantisano Terra, B.R. (2000) The future of the university and the university of the future: evolution of ivory tower to entrepreneurial paradigm. Research Policy, 29 (2), 313-330.

European Commission (2006) Competence Research Centre Programmes in Europe. Brussels: European Commission, Compera Network.

Fenno, R. (1978) Home Style: House Members in Their Districts. Boston. Little Brown.

Gennerud, H., Nordfors, L., \& Ericson, B. (2009) Process support, communication and branding: VINNOVA's VINNVÄXT programme. Stockholm: Gullers Grupp Informationsrådgivare AB and VINNOVA - Verket för Innovationssystem.

Gibbons, M., Limoges, C. and Scott, P. (2011) Revisiting Mode 2 at Noors Slot. Prometheus, 29 (4), 361-372.

Gibbons, M., Limoges, C., Nowotny, H., Schwartzman, S., Scott, P. and Trow, M. (1994) The New Production of Knowledge. London: Sage.

Göktepe, D. (2008). Inside the Ivory Tower- Inventors and Patents at Lund University, Monograph-PhD thesis, Lund University Publications ISBN: 978-91-977285-1-5

Government of Canada (2009) Networks of Centres of Excellence 20th Anniversary Report. Ottawa, Canada.

Government of Canada (2011) Networks of Centres of Excellence of Canada, www.nce-rce.gc.ca, accessed 20 January 2012.

Grant, K., Meyer, M., and Kuusisto, J. (2014) Can processes make relationships work? The Triple Helix between structure and action. Prometheus, 32 (4), 351-368.

Guba, E. G. and Lincoln, Y. S. (1994) Competing paradigms in qualitative research. In N. K. Denzin \& Y. S. Lincoln (Eds.), Handbook of Qualitative Research (pp. 105-117). Thousand Oaks, CA: Sage.

Gustafsson, R. and Järvenpää, S. (2017) Extending community management to industry-university-government organizations. R\&D Management 48 (1), 121-135.

Hellström, T. (2017) Centres of Excellence and Capacity Building: from Strategy to Impact. Science and Public Policy, https://doi.org/10.1093/scipol/scx082.

Hessels, L. K. and van Lente, H. (2009) Re-thinking new knowledge production: A literature review and a research agenda. Research Policy, 37, 740-760.

Howells, J. (2006) Intermediation and the role of intermediaries in innovation. Research Policy 35, 715-728.

Howells, J. and Edler, J. (2011) Structural innovations: towards a unified perspective? Science and Public Policy, 38 (2), 157-167.

Kavlie, D. (2010) The Centres for Research-based Innovation Scheme (SFI). Presentation. Oslo: Research Council of Norway.

Kavlie, D., Sleeckx, E., Struijk, C. and Schamp, T. (2010) Report on Monitoring and Evaluation of Competence Research Centres (CRC). COMPERA consortium.

Kingdom, J.W. (1995) Agendas, Alternatives and Public Policies, $2^{\text {nd }}$ ed., New York, HaperCollins

Knee, P. and Meyer, M. (2007) Global innovation environments - Study A. Bristol: HEFCE.

Koschatzky, K. and Stahlecker, T. (2010) New forms of strategic research collaboration between firms and universities in the German research system. Int. J. Technology Transfer and Commercialisation, 9 (1/2), 94-110.

Kuusisto, J. and Meyer, M. (2011) Study on Nordic User Driven Competence Centres. Unpublished report. Oslo: Nordic Innovation Center.

Lähteenmäki-Smith, K., Halme, K., Lemola, T., Piirainen, K., Viljamaa, K., Haila, K., Kotiranta, A., Hjelt, M., Raivio, T., Polt, W., Dinges, M., Ploder, M., Meyer, S., Luukkonen, T., Geroghiou, L. (2013), 'License to SHOK?' External evaluation of the Strategic Centres of Excellence for Science Technology and Innovation. Publications of the Ministry of Employment and the Economy, Innovation, 1/2013, Helsinki.

Leydesdorff, L. and Meyer, M. (2010) The decline of university patenting and the end of the Bayh-Dole effect. Scientometrics, 83 (2), 355-362.

Lundberg, M. (2010) Centres of Excellence in Research and Innovation. A management perspective. Presentation. Stockholm: Vinnova.

Lundvall, B- $\AA$. (1999) National Business Systems and National Systems of Innovation. International Studies of Management and Organisation, 29 (2), 60-77.

Martinelli, A.; Meyer, M.; Von Tunzelmann, G.N. (2008) Becoming an entrepreneurial university? A case study of knowledge exchange relationships and faculty attitudes in a medium-sized, research- oriented university. Journal of Technology Transfer, 33 (3), 259-283.

Mathieu, A.; Meyer, M., Van Pottelsberghe de la Potterie, B. (2008) Turning science into business: A case study of a major European research university. Science and Public Policy, 35 (9), 669-679.

Meyer, M., with Castro-Martinez, E., Kijenska, I., Candemir, B., Göktepe, D., Molas-Gallart, J., Tang, P., Klitkou, A., Kutinlahti, P., Inzelt, A., and Must, Ü. (2007) University patenting and IP management approaches in Europe. Report for the European Patent Office, December 2007,160 pages. 
Nowotny, H., Scott, P. and Gibbons, M. (2001) Re-Thinking Science - Knowledge and the Public in an Age of Uncertainty. Cambridge, UK: Polity Press.

Orlikowski, W. and Baroudi, J. (1991) Studying information technology in organisations: research approaches and assumptions. Information Systems Research, 2 (1), 1-28.

Pelkonen, A., Teräväinen, T. and Waltari, S. (2008) Assessing policy coordination capacity: higher education, science, and technology policies in Finland. Science and Public Policy, 35 (4), 241-252.

Performance Management Network Inc. (2012) Evaluation of the Business-Led Networks of Centres of Excellence (BL-NCE) Program. Final Report. Submitted to Corporate Planning and Policy, Natural Sciences and Engineering Research Council (NSERC), March 2012.

Pralahad, C. and Krishnan, M. (2008) The New Age of Innovation: Driving Co-Created Value Through Global Networks. New York, USA: McGraw Hill Books.

Ranga, M. and Etzkowitz, H. (2013) Triple Helix Systems: An Analytical Framework for Innovation Policy and Practice in the Knowledge Society. Industry and Higher Education 27 (4), 237-262.

RCN (2010) Midway evaluation of the Centres for Research-based Innovation. Evaluation Division for Innovation. Oslo: The Research Council of Norway.

Readman, J., Bessant, J., Neely, A., Twigg, D. (2018) Positioning UK research and technology organisations as outward-facing technology-bases. R\&D Management 48 (1), 109-120.

Reeve, D., and Anderson, A.H.; with Blessing, L.; Barton, D.; Clift, R.; Davis, K.; Delplancke-Ogletree, M.-P.; Stutzmann, M.; Skrivervik, A.; Koivunen, V.; Schreurs, D.; Thayne, I.; Bödker, S.; Rodgers, Y.; Sundby Avset, B.; Turner, A.; van der Zwaag, S.; Enomoto, M.; Takkinen, K.; Kulomaa, M.; Tanner, E.; Planell, J.; Hu, J., McKay, A.; Möhwald, H.; Seymour, J.; Ragauskas, A.; Tenkanen, M.; Braun, T.; O’Hare, G.; Welch, R.; Bach Knudsen, K.E. (2009) First Evaluation of the second, third and fourth round of Vinnova VINN Excellence Centres - FASTE, SUS, FUNMAT, CHASE, GHz, MOBILE LIFE, iPACK, HERO-M, PRONOVA, BIOMATCELL, WINGQUIST, SUMO, BIMAC INNO, WISENET and AFC. VINNOVA Report, VR 2009:34. Stockholm: Vinnova - Verket för Innovationssystem.

Rip, A. (2004) Strategic research, post-modern universities and research training. Higher Education Policy, 17 (2), 153-166.

Rip, A. (2011) The future of research universities. Prometheus, 29 (4), 443-453.

Schiller, D. (2011) Institutions and practice in cross-sector research collaboration: conceptual considerations with empirical illustrations from the German science sector. Science and Public Policy, 38 (2), 109-121.

Schwandt, T. (1994) Constructivist, interpretivist approaches to human inquiry. In N. K. Denzin \& Y. S. Lincoln (Eds.), Handbook of Qualitative Research (pp. 118-137). Thousand Oaks, CA: Sage.

Stern, P., Arnold, E., Carlberg, M., Fridholm, T., Rosemberg, C., \& Terrell, M. (2013) Long-term industrial impacts of the Swedish competence centres. Technopolis group VINNOVA Analysis, VA 2013:10. Stockholm: VINNOVA - Verket för Innovationssystem.

Stokes, D. E. (1997) Pasteur's Quadrant: Basic Science and Technological Innovation. Washington, D.C.: Brookings Institution Press.

Tekes (2011) Strategic Centres for Science, Technology and Innovation (SHOKs). Helsinki: Tekes.

Thune, T. and Gulbrandsen, M. (2011) Institutionalization of university-industry interaction: an empirical study of the impact of formal structures on collaboration patterns. Science and Public Policy, 38 (2), 99-107.

Turpin, T. and Fernández-Esquinas, M. (2011) Introduction to special issue: The policy rationale for cross-sector research collaboration and contemporary consequences. Science and Public Policy, 38(2), 82-86.

Van de Ven, A.H., and Johnson, P.E. (2006) Knowledge for Theory and Practice. Academy of Management Review, 31 (4), 802-821.

Van Looy, B., Debackere, K. and Andries, P. (2003) Policies to stimulate regional innovation capabilities via university-industry collaboration: an analysis and an assessment. R\&D Management, 33, 2, 209-229.

von Hippel, E. (1988) The Sources of Innovation. Oxford University Press.

von Hippel, E. (2005) Democratizing Innovation. Cambridge, MA, USA: MIT Press.

Weber, M.(1999) Essays in Economic Sociology. Ed by R Swedberg. Princeton, NJ: Princeton University Press. Whitley, R. (1992) Societies, Firms and Markets: the Social Structuring of Business Systems. London: Sage.

Yin, R. K. (2003) Case Study Research, Design and Methods, 3rd ed. Newbury Park: Sage Publications.

Zulkifli, A. (2009) Business-Led Networks of Centres of Excellence (BL-Networks). Presentation Trade Commission, Embassy of Canada, Oslo. 


\begin{tabular}{|c|c|c|c|}
\hline Country & Initiative & Funding/Duration & Brief description / 'Official mission' \\
\hline Sweden & $\begin{array}{l}\text { VINN Excellence } \\
\text { Centres }\end{array}$ & $\begin{array}{l}\text { - } \quad \text { EUR 20m p.a. for entire programme } \\
\text { - } \quad \text { total funding of EUR } 650 \mathrm{~m} \text { over up to } 10 \text { years, incl. EUR } 300 \mathrm{~m} \\
\text { investment from industry and others } \\
\text { - maximum amount of funding per project: EUR800k, a third of } \\
\text { which to be financed by partners, typically 5-10 members per } \\
\text { consortium. } \\
20 \text { centres supported by VINNOVA and } 4 \text { by other funding } \\
\text { agencies, } \\
\text { - First centres launched in } 2006 \text {, to run 5-10 years }\end{array}$ & 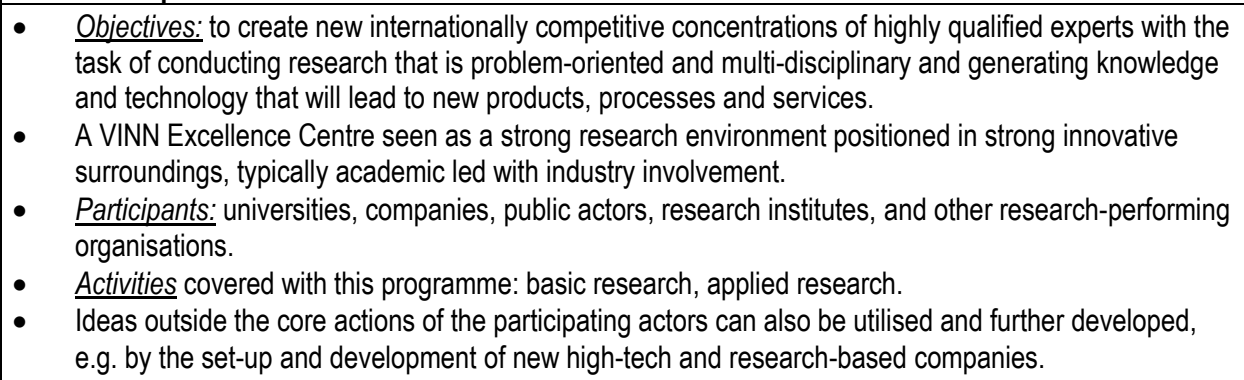 \\
\hline Norway & $\begin{array}{l}\text { CRI - Centres for } \\
\text { Research based } \\
\text { Innovation }\end{array}$ & $\begin{array}{l}\text { - EUR } 17.5 \mathrm{~m} \text { p.a. in public funding; total investment over entire } 8 \\
\text { year period: Euro } 300 \mathrm{~m} \text {. } \\
\text { - maximum amount of funding per project: } 50 \% \text {, at least } 25 \% \text { of } \\
\text { the funding is to come from the business partners } \\
\text { Programme duration: October } 2006 \text { - December } 2014 \text {, subject to } \\
\text { a successful mid-term evaluation after } 3.5 \text { years }\end{array}$ & $\begin{array}{l}\text { - Objectives: (1) encourage enterprises to innovate by placing stronger emphasis on long-term } \\
\text { research; (2) facilitate active alliances between innovative enterprises and prominent research } \\
\text { groups; (3) promote the development of industrially-oriented research groups that are on the cutting } \\
\text { edge of international research and are part of strong international networks; (4) stimulate researcher } \\
\text { training in fields of importance to the business community, and the transfer of research-based } \\
\text { knowledge and technology; } \\
\text { - } \quad \text { Activities: basic research, applied research, training and technology transfer }\end{array}$ \\
\hline Canada & $\begin{array}{l}\text { Business-led } \\
\text { Networks of } \\
\text { Centres of } \\
\text { Excellence } \\
\text { Program (BL- } \\
\text { NCE) }\end{array}$ & $\begin{array}{l}\text { - } 4 \text { BL-NCE centres set up } \\
\text { (compared to } 39 \text { Networks of Centres of Excellence ) } \\
\text { - Funding: around EUR 35million; } \\
\text { EUR 6.8-9.8 million per centre for 2009-13 } \\
\text { (EUR 1.7-2.5 million per year) } \\
\text { - Centre duration: } 4 \text { year, funding not renewable }\end{array}$ & $\begin{array}{l}\text { - Objective: BL-NCEs will foster a competitive and dynamic business environment to encourage S\&T } \\
\text { investments and create an 'Entrepreneurial Advantage': "The private sector will identify and lead new } \\
\text { research networks that address their priorities under the Networks of Centres of Excellence Program." } \\
\text { - } \quad \text { Goals: (1) fund large-scale collaborative networks to perform research and commercialization; (2) } \\
\text { enhance private sector innovation; (3) deliver economic, health, social and environmental benefits. }\end{array}$ \\
\hline Finland & $\begin{array}{l}\text { SHOK - Strategic } \\
\text { Centres }\end{array}$ & $\begin{array}{l}\text { - } \quad \text { Programme level funding: EUR } 300 \mathrm{~m} \text { p.a., } \\
\text { - } \quad \text { EUR } 40-60 \text { million annually are invested in research, within each } \\
\text { centre } \\
\text { - } \quad 60 \% \text { of research to be co-funded by industry } \\
\text { company will be responsible for the centre's operations }\end{array}$ & 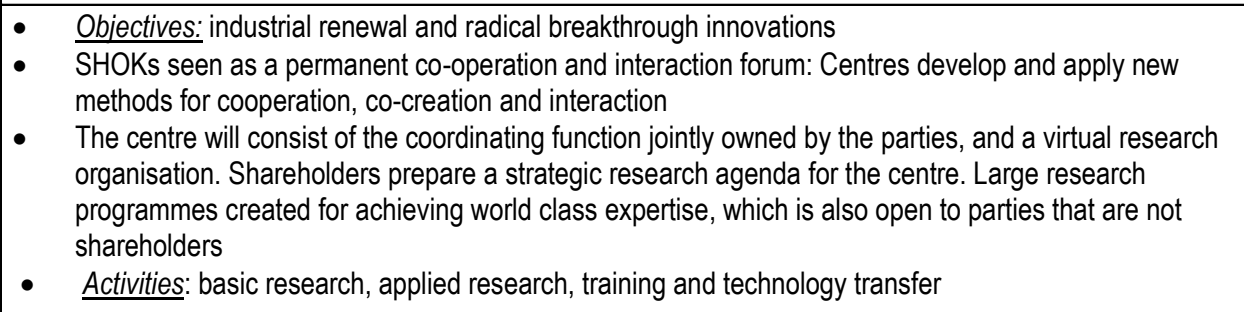 \\
\hline
\end{tabular}

Source: Kavlie (2010), Kavlie et al. (2010), Kuusisto \& Meyer (2011), Lundberg (2010), Tekes (2011), Zulkifli (2009), Government of Canada (2009, 2011), European Commission (2006) 